COMUNICAÇÃO CIENTÍFICA

\title{
EFEITO DO EXTRATO DE ALHO NA QUEBRA DE DORMÊNCIA DE MACIEIRAS ${ }^{1}$
}

\author{
RENATO VASCONCELOS BOTELHO²
}

RESUMO - Com o objetivo de avaliar o efeito do extrato de alho na quebra de dormência de macieiras, um experimento foi conduzido em pomar comercial das cultivares Royal Gala e Fuji Kiku, localizado no município de Guarapuava, região centro-oeste do Paraná. Os tratamentos foram os seguintes: T1 - testemunha; T2 - extrato de alho, e T3 - cianamida hidrogenada + óleo mineral a 3\%. As aplicações foram realizadas em 3 de setembro de 2004, no estádio fenológico de gema dormente. As avaliações da porcentagem de gemas brotadas foram realizadas semanalmente, entre o período de 17 de setembro e 6 de outubro de 2004. Para as duas cultivares, os melhores resultados foram verificados para o tratamento com cianamida hidrogenada e óleo mineral ( $71,3 \%)$. O tratamento com extrato de alho também promoveu a quebra de dormência de macieiras 'Fuji Kiku', com 40,6\% de gemas brotadas aos 35 dias após as aplicações, comparado a apenas $18,2 \%$ do tratamento-testemunha.

Termos para indexação: Malus domestica, maçãs, brotação, 'Royal Gala', 'Fuji Kiku'.

\section{EFFECT OF THE GARLIC EXTRACT ON DORMANCY BREAKING OF APPLE TREES}

\begin{abstract}
With the objective of evaluate the effect of garlic extract on dormancy breaking of apple trees, a trial was carried out in a commercial orchard of the Royal Gala and Fuji Kiku cultivars, located in Guarapuava, middle-west region of Paraná State, Brazil. The treatments were as following: T1 - control; T2 - garlic extract, and T3 - 0.45\% hydrogenated cyanamide $+3 \%$ mineral oil. The applications were accomplished on September $3^{\text {rd }}$, 2004, on phenological stage of dormant bud. The evaluations of sprouted buds percentage were carried out weekly, from September $17^{\text {th }}$ to October $6^{\text {th }} 2004$. For both cultivars, the best results were verified for the treatment with hydrogenated cyanamide and mineral oil (71.3\%). The treatment with garlic extract also promoted dormancy breaking of 'Fuji Kiku' apple trees, with $40.6 \%$ of sprouted buds after 35 days from the applications, compared to just $18.2 \%$ of the control. Index terms: Malus domestica, sprouting, apple fruits, 'Royal Gala', 'Fuji Kiku'.
\end{abstract}

As fruteiras de clima temperado caracterizam-se pela queda das folhas no final do ciclo vegetativo e entrada em dormência no inverno, permitindo a sua sobrevivência em condições de baixas temperaturas. Para que essas plantas iniciem um novo ciclo na primavera, é necessária a sua exposição a um período de frio, variável para cada espécie e cultivar (Petri et al., 1996).

No entanto, as cultivares de macieira mais plantadas no Sul do Brasil, como a Gala e a Fuji, assim como suas mutações, não têm suas exigências em frio plenamente satisfeitas, necessitando de tratamento com produtos químicos para a indução da brotação (Petri, 1997). Mesmo em regiões mais frias, como em São Joaquim-SC, a quebra de dormência química se faz necessária na maioria das vezes (Iuchi et al., 2002).

Muitos são os produtos que apresentam efeito na indução da brotação, podendo ser citados: óleo mineral, cianamida hidrogenada, dinitroortocresol, dinitrortobutilfenol, calciocianamida, thidiazuron, entre outros. No entanto, atualmente no Brasil, somente o óleo mineral e a cianamida hidrogenada são recomendados como indutores de brotação em macieiras (Petri et al., 2002).

Contudo, a necessidade de restringir cada vez mais o uso de substâncias sintéticas na condução dos pomares, preconizada pelo programa de Produção Integrada de Frutas, torna a questão da quebra de dormência química de plantas frutíferas um fator limitante para a atividade no Brasil (Sanhueza et al., 2003). O que torna este problema ainda mais alarmante, é a alta toxicidade da cianamida hidrogenada, que pode provocar ulcerações nos olhos, pele e trato respiratório, além de inibir a aldeído desidrogenase, levando à síndrome de acetaldeído (e.g.; vômito, hiperatividade parassimpática, dispnéia, hipotensão e desorientação). A Agência de Proteção Ambiental (EPA) classifica o Dormex ${ }^{\circledR}\left(490 \mathrm{~g} \mathrm{~L}^{-1}\right.$ de $\mathrm{H}_{2} \mathrm{CN}_{2}$ ) na mais alta categoria de toxicidade (categoria I) devido aos seus efeitos corrosivos na pele e nos olhos. Este alto risco de intoxicação pela exposição à cianamida hidrogenada levou à suspensão temporária das vendas do produto comercial Dormex ${ }^{\circledR}$ em 2002, na Itália, e revisão de sua regulamentação pelas autoridades da União Européia (Settimi et al., 2005).

$\mathrm{Na}$ busca por novas alternativas para a quebra de dormência de plantas frutíferas de clima temperado, Kubota \& Myamuki (1992) verificaram que a aplicação de pasta de alho na região do corte de poda de ramos de videiras 'Moscatel de Alexandria' estimulou a brotação de gemas de forma mais efetiva que a aplicação de solução a $20 \%$ de calciocianamida $\left(\mathrm{CaCN}_{2}\right)$, produto tradicionalmente utilizado na viticultura japonesa para

1 (Trabalho 083-06). Recebido em 20-06-2007. Aceito para publicação em : 16-03-2007.

2 Prof. Adjunto. Eng. Agr. Dr. Departamento de Agronomia, UNICENTRO. R. Simeão Camargo Varela de Sá, 03, 85040-080 Guarapuava-PR. E-mail: rbotelho@unicentro.br .

Rev. Bras. Frutic., Jaboticabal - SP, v. 29, n. 2, p. 403-405, Agosto 2007 
esta finalidade. Em outro trabalho, Kubota et al. (2000) constataram que aplicações de pasta de alho puro ou óleo de alho a $20 \%$ promoveram a quebra de dormência de gemas, sem apresentarem sintomas de fitotoxidez, em videiras 'Pione' e 'Thompson Seedless'.

Neste contexto, este trabalho teve como objetivo estudar o efeito do extrato de alho na quebra de dormência de macieiras 'Royal Gala' e 'Fuji Kiku', na região de Guarapuava-PR.

$\mathrm{O}$ experimento foi desenvolvido em pomar comercial localizado no município de Guarapuava (PR) (253' S e 51 $29^{\circ} \mathrm{O}$, $1.095 \mathrm{~m}$ de altitude). De acordo com os dados climáticos fornecidos pelo Instituto Tecnológico SIMEPAR, de maio a setembro de 2004, foram acumuladas 268 horas de frio $\left(d " 7.2^{\circ} \mathrm{C}\right)$ e 953 unidades de frio pelo Método da Carolina do Norte (Shaltout \& Unrath, 1983).

As plantas em $2^{\circ}$ ano e enxertadas sobre o porta-enxerto EM-9 estavam conduzidas no sistema de líder central com copa estreita em espaldeira. Os espaçamentos eram de 1,1 x 3,6 m para a cultivar Fuji Kiku e 0,9 x 3,6 m para a cultivar Royal Gala.

Para cada cultivar, foram realizados três tratamentos: T1 Testemunha (sem tratamento); T2 - Extrato de alho; T3 - cianamida hidrogenada a $0,45 \%$ (cv. Fuji Kiku) ou 0,35\% (cv. Royal Gala) + óleo mineral a 3,0\%. As aplicações foram realizadas em 3 de setembro de 2004, quando ambas as cultivares estavam no estádio fenológico de gema dormente. O delineamento experimental foi o em blocos casualizados, com três tratamentos, quatro parcelas subdivididas no tempo (avaliações), sete repetições e parcela experimental constituída por uma planta.

O extrato de alho foi preparado através da trituração de bulbilhos de alho descascados e posterior filtragem em tecido de algodão. A aplicação deste produto foi realizada mediante pincelamento de todas as gemas da macieira. Para o tratamento com cianamida hidrogenada e óleo mineral, foram utilizados os produtos comerciais DormexÒ (490 $\mathrm{g} \mathrm{L}^{-1}$ de cianamida hidrogenada) e TrionaÒ ( $80 \%$ de óleo mineral), aplicados mediante pulverização de solução aquosa em toda a parte aérea da planta.

Em cada planta, cinco ramos previamente selecionados e identificados foram avaliados para a variável porcentagem de gemas brotadas, considerando o estádio fenológico inicial de ponta-verde. As avaliações foram realizadas semanalmente, no período de 17 de setembro a 6 de outubro de 2004. Os resultados foram submetidos à análise de variância para parcelas subdivididas no tempo, estudando-se a interação entre os fatores.

Para o experimento com a cultivar Fuji Kiku, houve interação entre os fatores, sendo que o tratamento com cianamida hidrogenada e óleo mineral foi o que promoveu a maior antecipação e porcentagem de gemas brotadas, atingindo a média de 71,3\% aos 35 dias após aplicação (Figura 1). O modo de ação da cianamida hidrogenada e do óleo mineral na quebra de dormência de gemas ainda não está totalmente esclarecido, podendo estar relacionado aos seus efeitos no sistema respiratório das células e à interferência em alguns processos enzimáticos que controlam o repouso das plantas, como a inibição da catalase e a ativação de certas peroxidases (Taylorson \& Hendricks, 1977; Shulman et al.,1986).

O tratamento com extrato de alho também promoveu a brotação das gemas das macieiras cv. Fuji quando comparado ao tratamento-testemunha; no entanto, os resultados foram inferiores ao tratamento com cianamida hidrogenada e óleo mineral, atingindo uma média de 40,6\% aos 35 dias após aplicação (Figura 1). De acordo com Kubota et al. (1999), as substâncias no alho, que estimulam a quebra de dormência em plantas frutíferas, são compostos voláteis contendo enxofre e um grupo alil $\left(\mathrm{CH}_{2} \mathrm{CHCH}_{2}\right)$, particularmente dialil dissulfito, que é o sulfito mais abundante no alho. A exposição de estacas de videiras a voláteis de alho macerado ou óleo de alho comercial promove quebra de dormência de gemas (Kubota et al., 1999a) e exposições a voláteis de dialil di- e trissulfitos foram também efetivos (Kubota et al., 1999b). Entretanto, o modo de ação fisiológico destes compostos na quebra de dormência de gemas de plantas frutíferas ainda não foi esclarecido (Kubota et al., 2000).

Para a cultivar Gala, também houve interação entre os fatores estudados. O tratamento com cianamida hidrogenada $\mathrm{e}$ óleo mineral também promoveu a maior brotação das gemas, atingindo 55,1\% aos 35 dias após aplicação (Figura 2). O tratamento com extrato de alho não foi eficiente na quebra de dormência para esta cultivar de macieira, apresentando valores de porcentagem de brotação próximos aos da testemunha (Figura 2).

Constatou-se, neste trabalho, que o extrato de alho apresentou efeito na quebra de dormência de gemas de macieiras 'Fuji Kiku'; no entanto, os resultados ainda são insatisfatórios, necessitando de mais estudos para a sua possível aplicação prática na fruticultura comercial. Novas pesquisas, utilizando-se de formulações mais diluídas e adicionadas de adjuvantes, poderão futuramente trazer resultados mais promissores para uma possível substituição do uso da cianamida hidrogenada. As razões da ausência de efeitos do extrato de alho na quebra de dormência da macieira 'Royal Gala' são desconhecidas, podendo estar relacionadas a uma fitotoxidez pelo uso do produto não diluído.

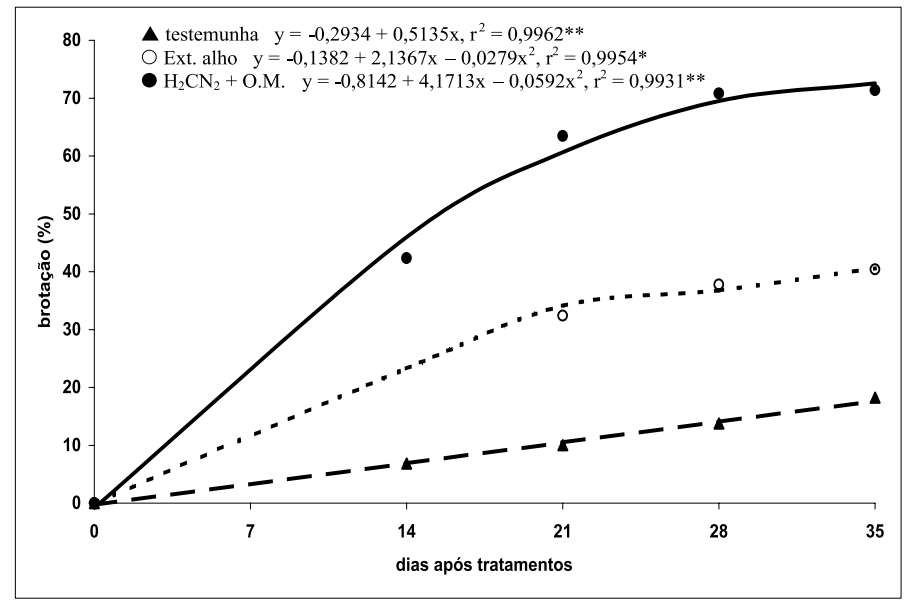

FIGURA 1 - Porcentagem de brotação de gemas de macieiras 'Fuji Kiku' submetidas a diferentes tratamentos para quebra de dormência (Guarapuava-PR, 2004). $(* P<0,05 ; * * P<0,01)$. 


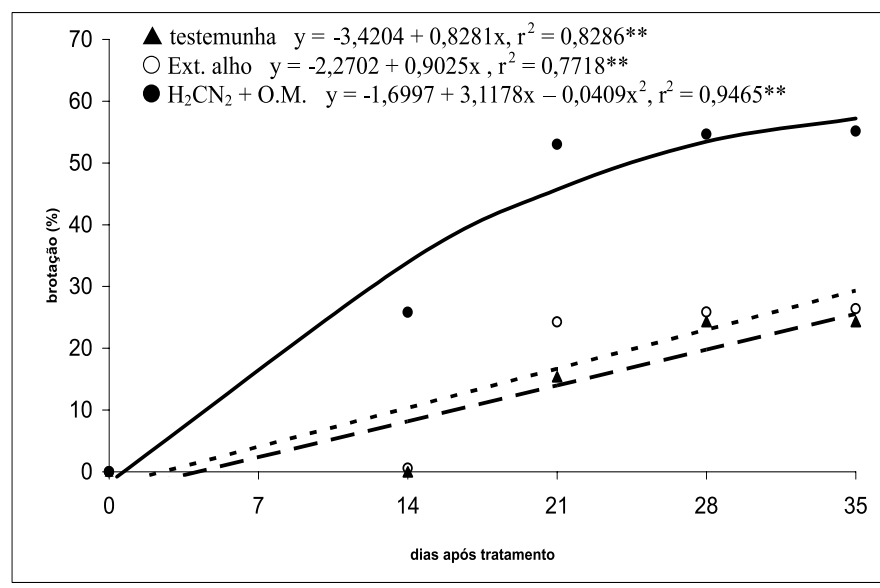

FIGURA 2 - Porcentagem de gemas brotadas de macieiras 'Royal Gala' submetidas a diferentes tratamentos para quebra de dormência (Guarapuava-PR, 2004).

( $\left.{ }^{*} P<0,05 ; * * P<0,01\right)$.

\section{REFERÊNCIAS}

IUCHI, V.L.; IUCHI, T.; BRIGHENTI, E.; DITRICH, R. Quebra de dormência da macieira (Malus domestica Borkh) em São Joaquim-SC. Revista Brasileira de Fruticultura, Jaboticabal, v.24, n.1, p.168-174, 2002.

KUBOTA, N.; MIYAMUKI, M. Breaking bud dormancy in grapevines with garlic paste. Journal of the American Society for Horticultural Science, Alexandria, v.117, n.6, p.898-901, 1992.

KUBOTA, N.; MATTHEWS, M.A.; TAKAHAGI, T; KLIEWER, W.M. Effects of garlic preparations and calcium and hydrogen cyanamides on budbreak of grapevines grown in greenhouses. American Journal of Enology and Viticulture, Davis, v.51, n.4, p.409-414, 2000.

Kubota, N.; Miyamuki, M.; Yamane,Y.; Kobayashi, A. Breaking bud dormancy in grapevine cuttings with garlic volatiles. Journal of the Japanese Society for Horticultural Science, Kyoto, v.68, n.6, p.927-931. 1999a.

KUBOTA, N.; YASUSHI, Y.; KOJI, T.; KAZUYOSHI, K.; TESUO, H.; SHOJI, N. Identification of active substances in garlic responsible for breaking bud dormancy in grapevines. Journal of the Japanese Society for Horticultural Science, Kyoto, v.68, n.6 p.1111-1117, 1999b.

PETRI, J.L.; PALLADINI, L.A.; SCHUCK, E. et al. Dormência e indução da brotação de fruteiras de clima temperado. Florianópolis: EPAGRI, 1996. 110p. (Boletim técnico, 75)

PETRI, J.L. Indução de brotação de macieira por cianamida hidrogenada e óleo mineral sob influência da temperatura. Pesquisa Agropecuária Brasileira, Brasília, v.32, n.1, p.7175, 1997.

PETRI, J.L.; PALLADINI, L.A.; POLA, A.C. Dormência e indução da brotação da macieira. In: EPAGRI. Manual da cultura da macieira. Florianópolis, 2002. p.261-298.
SANHUEZA, R.M.V.; ANDRIGUETO, J.R.; KOSOSKI, A.R. Situação atual da produção integrada de frutas no Brasil. In: MELO, G.W.B.; SEBBEN, S.S. (Eds.). SEMINÁRIO BRASILEIRO DE PRODUÇÃO INTEGRADA DE FRUTAS, 5., Bento Gonçalves, 2003. Anais... Bento Gonçalves: Embrapa-CNPUV, 2003.p.23-25.

SETTIMI, L.; DAVANZO, F.; FARAONI, MICELI, G.; RICHMOND, D.; CALVERT, G.M. Update: Hydrogen cyanamide-related illnesses-Italy, 2002-2004. Morbidity and Mortality Weekly Report, Atlanta, v.54, n.16, p.405-408, 2005.

SHALTOUT, A.D.; UNRATH, C.R. Rest completion prediction model for 'Starkrimson Delicious' apples. Journal of the American Society for Horticultural Science, Alexandria, v.108, p.957-961, 1983.

SHULMAN, Y.; NIR, G.; LAVEE, S. Oxidative process in bud dormancy and the use of hydrogen cyanamide in breaking dormancy. Acta Horticulturae, Leiden, n. 179, p.141-148, 1986.

TAYLORSON, R.B.; HENDRICKS, P. Dormancy in seeds. Annual Review of Plant Physiology, Palo Alto, v.28, p.331-354, 1977. 